\title{
Spontaneous rupture of adrenal haemangioma mimicking abdominal aortic aneurysm rupture
}

Piotr Paluszkiewicz ${ }^{1,2}$, Iwona Ambroziak³ ${ }^{3}$ Katarzyna Hołyńska-Dąbrowska³, Zofia Siezieniewska-Skowrońska ${ }^{4}$, Andrzej Paluszkiewicz ${ }^{5}$

${ }^{1}$ Department of Surgery and Surgical Nursing, Medical University of Lublin, Poland
2Department of Surgery, St John Hospital of Lublin, Poland
${ }^{3}$ Department of Anaesthesiology and Intensive Care, St John Hospital of Lublin, Poland
${ }^{4}$ Department of Histopathology, St John Hospital of Lublin, Poland
${ }^{5}$ Department of Vascular Surgery, John Paul II Hospital, Zamość, Poland

Submitted: 14 May 2008

Accepted: 23 September 2008

Arch Med Sci 2010; 6, 1: 122-125

DOI 10.5114/aoms.2010.13519

Copyright @ 2010 Termedia \& Banach

\begin{abstract}
Serious bleeding from a ruptured adrenal mass limits preoperative diagnostics and can necessitate urgent laparotomy to control blood loss. A 45-year old man underwent an emergency laparotomy due to severe retroperitoneal haemorrhage causing hypovolaemia. Detailed retroperitoneal dissection after splenectomy and clamping of the abdominal aorta revealed bleeding from a ruptured haemangioma of the left adrenal gland. Following a left adrenalectomy, the patient returned to a stable haemodynamic state. Adrenal haemangiomas are rare, but may cause spontaneous life-threatening haemorrhage.
\end{abstract}

Key words: haemorrhage, shock, haemostasis, retroperitoneal, adrenal haemangioma.

\section{Introduction}

In non-traumatic cases, the most common cause of a severe retroperitoneal haemorrhage in adults is a rupture of the abdominal aorta or any other retroperitoneal large vessel aneurysm [1]. Cases of spontaneous rupture of adrenal masses in the literature include: phaeochromocytoma [2], myelolipoma [3], cortical adenoma [4], adrenocortical carcinoma and metastatic tumours [5].

Incidental adrenal mass is a common finding and its characteristics are extensively studied using computed tomography and magnetic resonance imaging [6]. Adrenal haemangiomas are usually diagnosed as unilateral non-active endocrine tumours sometimes mimicking the masses of neighbouring organs [7]. Fewer than 40 cases of adrenal haemangiomas have been described in English literature [8]. Most of the described cases were asymptomatic and were found during autopsy [9]. Unusual bleeding from a spontaneously ruptured adrenal haemangioma, presenting with haematomas of the scrotum and penis but no signs of massive haemorrhage, was reported by Fernandez Ruiz et al. [10]. Haemorrhages into a large adrenal haemangioma without tumour rupture were presented in two other cases $[8,11]$. Presented in this case report is the fourth reported incidence of adrenal haemangioma causing retroperitoneal bleeding.

\section{Corresponding author:}

Piotr Paluszkiewicz MD, PhD Ass. Prof.

Department of Surgery and Surgical Nursing

Medical University

6 Dr. W. Chodzki St

PL-20090 Lublin, Poland

Phone/fax +48 817402680

E-mail:ppalusz@uhc.com.pl 


\section{Case report}

A previously healthy 45-year old male (body weight of $68 \mathrm{~kg}$ ) was admitted to our emergency department with spontaneous sudden onset pain in the left lumbar region and concomitant nausea and flatulence. The patient was pale, in a cold sweat, with a systolic blood pressure of $70 \mathrm{mmHg}$ and despite a heart rate (HR) of $80 \mathrm{bpm}$, suggesting the presence of haemorrhage. Both the left lower quadrant of the abdomen and the epigastrium were tender on palpation. Signs of peritoneal irritation or a palpable intra-abdominal mass were absent. Ultrasonography of the abdomen revealed an irregular and heterogeneous mass in the retroperitoneal space and in the hilum of the spleen with an obvious fluid collection in the left subphrenic space. The contours of the aorta were indistinct. The left kidney was displaced inferiorly.

After initial resuscitation with a rapid intravenous infusion of $500 \mathrm{ml}$ of Ringer's lactate solution and $500 \mathrm{ml}$ of $10 \%$ hydroxyethyl starch, the patient became haemodynamically stable (Table I). Immediately following treatment, the blood haemoglobin level decreased from 12.9 to $11.8 \mathrm{~g} / \mathrm{dl}$, and white blood count increased from 11.0 to $14.7 \mathrm{~K} / \mu \mathrm{l}$. The platelet count was $194 \mathrm{~K} / \mu \mathrm{l}$.

Once the patient became haemodynamically stable, he was sent for an emergency CT scan. During this investigation however, he yet again displayed the symptoms and signs of hypovolaemic shock. The patient responded well to another infusion of $500 \mathrm{ml}$ of Ringer's lactate solution and $500 \mathrm{ml}$ of $10 \%$ hydroxyethyl starch.

An urgent xyphoumbilical laparotomy was performed, revealing a giant left-sided retroperitoneal haematoma, and $200 \mathrm{ml}$ of red blood surrounding the splenic hilum was collected. The suspicion of a rupture of an aneurysmal splenic artery and the need to mobilise the left sided retroperitoneal viscera to fully expose the abdominal aorta prompted us to perform the Mattox manoeuvre with a subsequent splenectomy. After suprarenal clamping of the abdominal aorta, the normal aorta and renal vessels were inspected. Further meticulous dissection of the left retroperitoneal space produced a disintegrated left adrenal gland, fragmented within a mass of thrombus and serosanguinous fluid. After the removal of approximately 1.5 I of this thrombus and blood, good surgical haemostasis was achieved by ligation of the bleeding inferior and superior adrenal arteries. The haemodynamic stability of the patient was then ensured.

Surgery lasted $70 \mathrm{~min}$. During the procedure 11 of Ringer's lactate solution and $500 \mathrm{ml}$ of $10 \%$ hydroxyethyl starch were infused. After surgery the patient's core body temperature was $36.5^{\circ} \mathrm{C}$.

During the first $24 \mathrm{~h}$ after surgery, the patient received a further infusion of 1.5 I of Ringer's lactate solution, 1 I of hydroxyethyl starch and 2 units of fresh frozen plasma. His haemoglobin level dropped to $7.4 \mathrm{~g} / \mathrm{dl}$ during the first postoperative day. Packed red blood cell transfusion was avoided. Bowel peristalsis returned on the second postoperative day. The patient left hospital fit and well on the eighth postoperative day.

Histological examination of the removed thrombus revealed fragmented tissues of cavernous haemangioma and left suprarenal gland (Figure 1). There were no signs of malignancy.

The patient was routinely followed up 9 months later and did not show any symptoms of any other haemangiomas or dysfunction of the right adrenal gland.

\section{Discussion}

Emergency surgery in haemodynamically unstable patients can be life-saving [1]. In this case, preoperative testing was not completed, including visualisation of any ruptured aneurysm morphology by CT angiography, Doppler ultrasonography, or other imaging techniques. Precise visualisation of large retroperitoneal vessels and confirmation of their integrity may have prevented this patient's splenectomy and abdominal aorta clamping. We believe that CT angiography performed in haemodynamically stable patients may significantly reduce iatrogenic trauma as it allows optimal planning of the surgical approach and techniques for focused isolation of the bleeding site.

Ultrasonography, suggested as the first step in investigation and elucidation of acute internal bleeding, was unsatisfactory in this case and not

Table I. Clinical data in patient with ruptured adrenal haemangioma prior to definitive surgical blood control

\begin{tabular}{|lccccc|}
\hline & On admission & $\begin{array}{c}\text { After initial } \\
\text { resuscitation }\end{array}$ & $\begin{array}{c}\text { Before CT } \\
\text { scanning }\end{array}$ & $\begin{array}{c}\text { During introduction } \\
\text { to general anaesthesia }\end{array}$ & $\begin{array}{c}\text { Before aorta } \\
\text { clamping }\end{array}$ \\
\hline Mean blood pressure $[\mathrm{mmHg}]$ & 50 & 73 & 45 & 55 & 50 \\
\hline Heart rate $[\mathrm{bpm}]$ & 80 & 70 & 96 & 105 & 115 \\
\hline $\mathrm{SpO}_{2}[\mathrm{kPa}]$ & 8.8 & & 8.4 & 13.0 & 13.0 \\
\hline Hourly urine output $[\mathrm{ml}]$ & 40 & 80 & 20 & 20 & 20 \\
\hline Infused fluids volume $[\mathrm{l}]$ & 1 & & 1 & 1.5 & \\
\hline
\end{tabular}




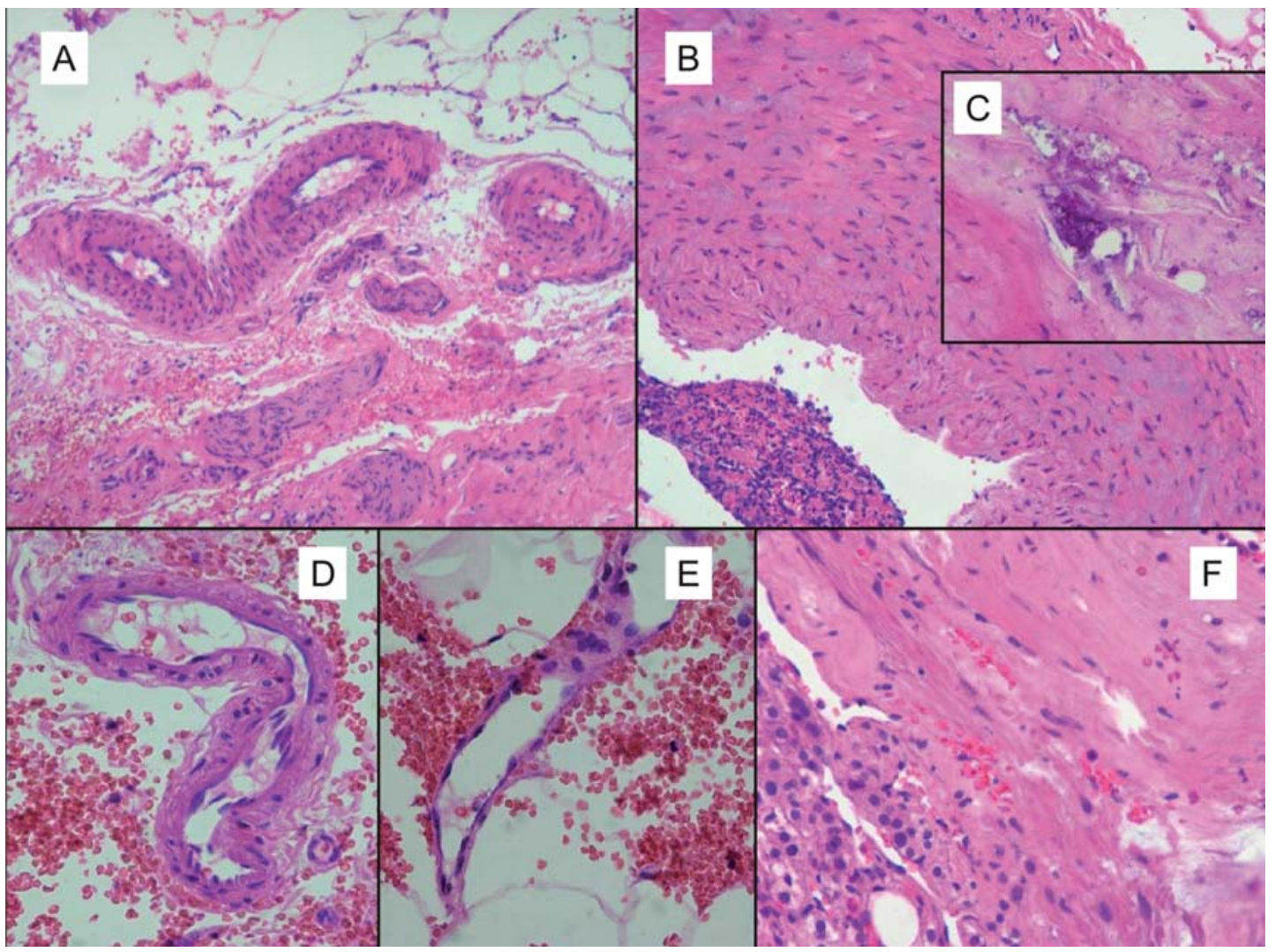

Figure 1. The thickened-wall arteries were found in the peri-adrenal space. Between the vessels adipose and connective tissues were visualized (A). The magnification showed a considerably marked elastic layer of arterial wall (B) and focused calcifications (C). Additionally, near arterial vessels some thin-wall veins were presented (D, E). These vascular malformations were existed into adrenal gland tissue (F). $4 \mu \mathrm{m}$ thick sections stained H\&E. Magnifications $100 \times(\mathrm{A})$, $200 \times(B)$ and $400 \times(C-F)$

sensitive enough to recognize a retroperitoneal haemorrhage from an adrenal haemangioma [5]. Valid diagnostic tools in such cases are subtracted arteriography, CT angiography and T2-weighted spinecho MR imagining [12]. Pathognomonic symptoms seen with adrenal haemangioma involve unilateral adrenal enlargement, cystic degeneration and calcification [13]. The dystrophic calcification (Figure 1C) or metaplastic ossification of haemangioma tissue should be differentiated from metastatic osteogenic malignant tumours [14] and from adrenal tuberculosis, which is usually observed in both adrenal glands [15]. In some unusual cases, bleeding into the tumour mass may mimic adrenal haemangioma [16].

The detailed histological examination of fragments of the adrenal gland (around $1.5 \mathrm{~cm}$ in diameter), independently by two pathologists, revealed dilated blood vessels with thickened walls partially grown into the adrenal tissue. The vessel walls were PAS positive and immunohistochemically lacked actin staining (not shown).

The clinical features of adrenal haemangioma may vary from asymptomatic to life-threatening bleeding [16]. Symptomatic adrenal haemangiomas were observed only in patients with large masses and were a consequence of the tumour's compression of neighbouring structures or of the destruction of endocrine-active adrenal tissue [12]. The presence of either adrenal hypo- or hyperactivity associated with adrenal haemangioma has been well established [9]. For instance, hormonal hypersecretion does not rule out the presence of a haemangioma of the adrenal gland [17]. In some cases, sudden lumbar pain was observed during bleeding into the tumour [2, 5, 9-12, 18]. In this particular case of left adrenal haemangioma rupture, sudden left lumbar pain and haemorrhagic shock were the first symptoms.

Because of the suspicion of a splenic artery aneurysm rupture, an immediate splenectomy was performed in this case. Fortunately, this resection helped expose the aorta and the left retroperitoneal space. This approach, under such critical conditions, allowed faster diagnosis and haemostasis. Fatal or debilitating post-haemorrhagic coagulopathy, resulting from persistent severe retroperitoneal bleeding, was thus avoided. It has been suggested that severe retroperitoneal haemorrhage may be successfully treated with recombinant factor VIla [19], especially in blood coagulation disorders. 
The reported operative procedure required rapid surgical haemostasis and concurrent correction of hypovolaemia and blood constitution. In our opinion, this urgent surgery with meticulous dissection of the retroperitoneal space with rapid and effective haemostasis resulted in a successful outcome. Moreover, we feel that this focused haemostasis is the optimal management in patients with uncontrolled non-coagulopathic bleeding. Delaying cessation of such massive bleeding is usually associated with large volume exsanguination or often severe complications such as multiple organ failure or postoperative sepsis. These events prolong total hospital stay and increase the final costs of treatment.

\section{Acknowledgments}

Diagnosis confirmation from Bozena BanachJarosz, Department of Environmental Pathology, Institute of Agricultural Medicine, Lublin, Poland is gratefully acknowledged.

\section{References}

1. Pode D, Caine M. Spontaneous retroperitoneal haemorrhage. J Urol 1992; 147: 311-8.

2. Orikasa K, Namima T, Ohnuma T, Munakata M, Kimura N, Arai Y. Spontaneous rupture of adrenal pheochromocytoma with capsular invasion. Int J Urol 2004; 11: 1013-5.

3. Nakajo M, Onohara S, Shinmura K, Fujiyoshi F, Nakajo M. Embolization for spontaneous retroperitoneal hemorrhage from adrenal myelolipoma. Radiat Med 2003; 21: 214-9.

4. Anderson WM, Timberlake GA. Massive retroperitoneal haemorrhage from an asymptomatic adrenal cortical adenoma. Report of a case. Am Surg 1989; 55: 299-302.

5. Kawashima A, Sandler CM, Ernst RD, et al. Imaging of nontraumatic hemorrhage of the adrenal gland. Radiographics 1999; 19: 949-63.

6. Ishigami K, Stolpen AH, Sato Y, Dahmoush L, Winfield HN, Fajardo LL. Adrenal adenoma with organizing hematoma: diagnostic dilemma at MRI. Magn Resonan Imaging 2004; 22: 1157-9.

7. Yeon YK, Kim RJ, An YS, et al. A case of adrenal hemangioma mimicking a pancreatic tail tumor. J Korean Soc Endocrinol 2008; 23: 62-5.

8. Forbes TL. Retroperitoneal hemorrhage secondary to a ruptured cavernous haemangioma. Can I Surg 2005; 48: 78-9.

9. Auh YH, Anand J, Zirinsky K, Kazam E. Adrenal Haemangioma: a case report. J Comput Tomography 1986; 10: 57-9.

10. Fernandez Ruiz M, Diez Ferez P, Vizcaino Lopez A, et al. Adrenal hemangioma: unusual cause of retroperitoneal hemorrhage [Spanish]. Arch Esp Urol 1995; 48: 82-5.

11. González Muñoz GF, Martínez Alarcón M, Fernández García ML. Adrenal hemangioma of atypical presentation. Bibliographical review [Spanish]. Arch Esp Urol 1998; 51: 191-4.

12. Boraschi P, Campatelli A, Di Vito A, Perri G. Haemorrhage in cavernous hemangioma of the adrenal gland: US, CT and MRI appearances with pathologic correlation. Eur J Radiol 1995; 21: 41-3.
13. Yamada T, Ishibashi T, Saito H, et al. Two cases of adrenal hemangioma: CT and MRI findings with pathological correlations. Radiation Med 2002; 20: 51-6.

14. Foehner M, Hanisch U, Noack B, Hakenberg OW, Wirth MP. Ossifying cavernous haemangioma masquerading as adrenal tuberculosis. J Urol 2000; 163: 894-5.

15. Korobkin M, Francis IR. Imaging of adrenal masses. Urol Clin North Am 1997; 24: 603-22.

16. Hamrick-Turner JE, Cranston PE, Shipkey FH. Cavernous haemangioma of the adrenal gland: MR findings. Magn Resonan Imaging 1994; 12: 1263-7.

17. Ng AC, Loh HL, Shum CF, Yip SK. A case of adrenal cavernous hemangioma presenting with progressive enlargement and apparent hormonal hypersecretion. Endocr Pract 2008; 14: 104-8.

18. Saeger W. Pathology of adrenal neoplasm's. Minerva Endocrinol 1995; 20: 1-8.

19. Danilos J, Goral A, Paluszkiewicz P, Przesmycki K, Kotarski J. Successful treatment with recombinant factor Vlla for intractable bleeding at pelvic surgery. Obstet Gynecol 2003; 101: 1172-3. 